\title{
Correction to: What is a plant nutrient? Changing definitions to advance science and innovation in plant nutrition
}

\author{
Patrick H. Brown · Fang-Jie Zhao • \\ Achim Dobermann
}

Published online: 22 February 2022

(C) Springer Nature Switzerland AG 2022

\section{Correction to: Plant Soil https://doi.org/10.1007/s11104-021-05171-w}

The original version of the article contained incorrect in-text language in the Abstract section and in conclusion section.

This Author's corrections are presented below.

We would like to request a change in the text in abstract deleting the word 'needed' and replacing it with the bolded text below. The same change can also be made in the 'Moving Forward section at end of manuscript:

A mineral plant nutrient is an element which is essential or beneficial for plant growth and

The original article can be found online at https://doi.org/ 10.1007/s11104-021-05171-w.

\section{P. H. Brown}

Department of Plant Science, University of California,

Davis, One Shields Ave, Davis, CA 95616, USA

F.-J. Zhao

College of Resources and Environmental Sciences, Nanjing Agricultural University, Nanjing 210095, China

A. Dobermann $(\bowtie)$

International Fertilizer Association (IFA), 49 avenue

d'Iena, 75116 Paris, France

e-mail: adobermann@fertilizer.org development or the quality attributes of the harvested product of a given plant species grown in its natural or cultivated environment.

The inclusion of the word 'needed' in the original text was inadvertent, is scientifically vague and inconsistent with subsequent text in the original version. The proposed change adds clarity and scientific precision.

The original article has been corrected.

Publisher's note Springer Nature remains neutral with regard to jurisdictional claims in published maps and institutional affiliations. 